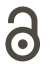

OPEN ACCESS

EDITADO POR

- Miguel Oliveira, Jr. (UFAL)

- René Almeida (UFS)

AVALIADO POR

- Leonor Scliar-Cabral (UFSC)

- Maria Elias Soares (UFC)

DATAS

- Recebido: 09/11/2019

- Aceito: 14/01/2020

- Publicado: 09/07/2020

COMO CITAR

MATEUS, Maria Helena Mira (2020). A Linguística, esta ciência que nos identifica e nos envolve. Cadernos de Linguística, v. 1, n. 1, p. 01-16.
ENSAIO TEÓRICO

\section{A LINGUÍSTICA, ESTA CIÊNCIA QUE NOS IDENTIFICA E NOS ENVOLVE}

\author{
Maria Helena Mira MATEUS (iD \\ Faculdade de Letras - Universidade de Lisboa
}

\section{RESUMO}

A parte inicial da conferência desenvolve e exemplifica a afirmação de que, no âmbito do estudo da linguagem, sempre conviveram diversas formas de conhecimento que vão das abordagens filosóficas e históricas às construções teóricas e formalizadas, passando pelas descrições pré-teoréticas e pelas aplicações em domínios de grande diversidade. Na segunda parte da conferência apresentam-se instrumentos de análise linguística decorrentes da interação entre lógica e matemática. Em relação à investigação atual, explicitam-se alguns exemplos da contribuição da ciência genética para a discussão da natureza da linguagem e apresentam-se as perspetivas criacionista e evolucionista como campos de investigação na aquisição de sistemas de conhecimento, com especial menção à aquisição da linguagem.

\section{ABSTRACT}

The initial part of this conference develops and demonstrates that, within the study of language, diverse forms of knowledge have always coexisted, ranging from philosophical and historic approaches to theoretical and formal constructions, including the pre-theoretical descriptions and the applications in domains of great diversity. In the second part of the conference, there is a presentation of instruments of linguistic analysis that stem from the interaction between logic and mathematics. With regards to the current investigation, some examples of the contribution of genetic science are explained for a discussion on the nature of language, and the creationist and evolutionist 
perspectives are presented as fields of investigation for the acquisition of systems of knowledge, with special mention to the acquisition of language.

PALAVRAS-CHAVE

Ciência; Gramática Generativa; Funcionalismo Linguístico.

KEYWORDS

Science; Generative Grammar; Linguistic Functioning. 


\section{A LINGUÍSTICA, ESTA CIÊNCIA QUE NOS IDENTIFICA E NOS ENVOLVE}

As minhas primeiras palavras são para agradecer o convite que recebi para proferir uma conferência no ambiente jubiloso dos 50 anos da ABRALIN. Agradeço à organização deste Congresso - que promete ser um evento a não esquecer - o convite que muito me honra e me dá grande prazer. Igualmente agradeço à Universidade Brasileira a atenção generosa e a amizade indefetível que sempre encontrei durante mais de quarenta anos, nos muitos momentos e nas variadas situações em que falei sobre Linguística.

De entre os temas que me pareceram de interesse para esta circunstância, lembrei um que desenvolvi em 2001, em Fortaleza, também a convite da organização do II Congresso da ABRALIN. Chamava-se então "A linguística e o conhecimento científico da linguagem". Aqui em Maceió, fui um pouco mais 'romântica' e passei a chamar-lhe $A$ Linguística, esta ciência que nos identifica e nos envolve. Na primeira parte da conferência apresento, de forma sumária, alguns marcos da investigação que muitos linguistas fizeram na procura de respostas para desvendar "os mistérios da ciência da linguagem". Correspondendo à reconstrução e atualização do tema, integro na segunda parte uma apresentação de novas perspetivas que representam avanços científicos e que vão, assim, iluminando o caminho que os linguistas procuram percorrer. Como em todas as ciências habitualmente denominadas sociais e humanas, pode afirmar-se que no âmbito do estudo da linguagem convivem diversas formas de conhecimento que vão das abordagens filosóficas e históricas às construções teóricas e formalizadas, passando pelas aplicações em domínios de grande diversidade.

Como disse em 2001 e me apraz repetir agora, ${ }^{1}$ essa multiplicidade de tratamentos decorre da própria natureza da linguagem verbal, forma preferencial de comunicação entre os homens. A linguagem é, simultaneamente, veículo de integração do homem na comunidade e fator constituinte da sua construção como indivíduo. A inter-relação da atividade linguística com os factos históricos e sociais, com o universo psicológico e com a criação artística coloca o estudo da linguagem e das línguas no centro de uma constelação formada por múltiplas comunicações com outras formas de comportamento humano. Mais: a especificidade do uso da linguagem verbal, de que resulta uma coincidência entre o objeto de análise e o meio com que se explicita e produz, esta análise ("é com palavras que se estudam as palavras") permite, estimula e valoriza interpretações subjetivas e acientíficas. 
Por todas estas razões tem sido longo e árduo o caminho dos que acreditam que é possível tomar a linguagem e as línguas como objeto de análise científica. Como muitos outros linguistas, no concreto do meu trabalho sobre a língua não sei entender a análise dessa magnífica faculdade humana senão como uma prática científica. Na verdade, "estudar as palavras com palavras" é levar ao extremo limite o conceito de autoreferência ${ }^{2}$ que, embora produza uma circularidade em relação ao próprio objeto de análise, tem todavia a consequência positiva de trazer à consciência esse objeto, neste caso, a linguagem e as línguas. Mas trazê-lo à consciência não significa explicá-lo. Como conciliar, então, estas duas questões, e por que insistir nesta perspetiva científica? Façamos um pouco de história que é saudável, instrutivo e esclarecedor.

\section{SÉCULOS XVIII E XIX - MÉTODO COMPARATISTA}

Comecemos a nossa viagem na viragem do século XVIII para o XIX. Na Europa, o estudo das línguas centrava-se na comparação entre línguas presumivelmente aparentadas, estudo que beneficiava dos trabalhos taxinómicos e classificatórios desenvolvidos por Carl Lineu. ${ }^{3}$ A partir do estudo comparado das línguas europeias, focado sobretudo nas modificações das vogais e consoantes das formas verbais, modificações que se tornavam evidentes com o passar do tempo, os linguistas incluíram no seu campo de análise algumas línguas orientais de entre as quais se destacava o sânscrito ${ }^{4}$. O aprofundamento da análise comparada entre línguas europeias e línguas orientais trouxe ao estudo das línguas grande incremento. Ao mesmo tempo que se retomava a questão da origem das línguas através do contacto entre línguas de procedências muito distantes, aprofundou-se o conhecimento e o estudo das línguas indo-europeias estabelecendo relações genealógicas entre elas.

Foi neste ambiente que William Jones 5 apresentou, em 1786, na Sociedade Asiática de Bengala, uma comunicação de grande pertinência sobre o sânscrito. Nesta comunicação William Jones afirmava que o sânscrito tinha um estreito parentesco com o latim, o grego

2 Sobre o conceito de auto-referência e as suas consequências para o conhecimento científico, ver Hofstadter (1999), sobretudo o prefácio à $2^{a}$ edição.

3 Carl Lineu foi um notável médico sueco que no século XVIII criou estudos sob a forma de taxonomias na área da botânica, da zoologia e de outras ciências naturais.

4 Nesta análise comparada tentava-se compreender a causa das mudanças, ou modificações, das línguas, ou seja, a causa da sua evolução.

5 William. Jones, filólogo e jurista inglês (1746-1794), afirmava que o sânscrito apresentava afinidades com o latim, o grego e o persa, sendo portanto admissível que todas essas línguas tivessem uma origem comum. Para William Jones o sânscrito tinha uma estrutura "maravilhosa". Estas afirmações permitiram a William Jones sugerir que essas línguas seriam derivadas de uma fonte comum que talvez já não existisse. 
e o persa, parentesco demonstrável no estudo das respetivas conjugações. Estas afirmações levaram William Jones a sugerir que essas línguas "são derivadas de uma fonte comum" que talvez já não existisse.

Outros linguistas comparativistas foram Jacob Grimm, Rasmus Rask e Franz Bopp. Este último trabalhou sobre a formação da gramática da língua portuguesa. Os estudos destes linguistas foram evidenciando as correspondências fonéticas e morfológicas que eram detetáveis na análise das várias línguas presumivelmente aparentadas. Perante as evidentes mudanças que era possível detetar nas línguas em estudo, os linguistas conhecidos como neogramáticos fizeram afirmações quase dogmáticas com o objetivo de explicar a evolução das línguas. Foi durante o século XIX que os neogramáticos propuseram a existência de leis fonéticas. ${ }^{6}$ Para os neogramáticos, as leis fonéticas, como o nome indica, aplicavam-se sempre que o elemento e o seu contexto correspondiam à definição da lei. Além desta questão da evolução das línguas, interessa sublinhar duas importantes áreas que manifestaram um significativo progresso durante a segunda metade do século XIX: os estudos de fonética e o crescente interesse pela descrição das línguas vivas. O desenvolvimento da fonética baseada em métodos experimentais beneficiou do progresso da física e das ciências naturais. A construção de instrumentos adequados à análise do som da fala, e dos movimentos articulatórios ligados à sua produção, forneciam o material necessário para o avanço dos estudos das línguas vivas.

A pouco e pouco, a análise comparada das línguas foi abrindo caminho para o estabelecimento da relação genealógica. As árvores genealógicas das línguas (ou de uma língua) permitem representar com facilidade as relações entre as procedências de uma língua a partir de outra ou outras. Numa árvore genealógica, ${ }^{7}$ podem visualizar-se de forma fácil os antepassados ou os descendentes de uma língua, ou das línguas que são mães, irmãs, primas ou filhas. Essa perspetiva sintonizou-se com os métodos científicos contemporâneos: o entendimento da língua como um organismo vivo que nasce, cresce e morre aproximou o seu estudo das hipóteses formuladas por Charles Darwin, ${ }^{8}$ sobre a origem e evolução das espécies, a sua evolução por meio de uma seleção natural.

\footnotetext{
6 Para os neogramáticos, as "leis fonéticas" aplicavam-se sempre que um elemento e o seu contexto correspondiam à definição da lei (por exemplo: na formação do português foi pela aplicação de uma lei fonética que as consoantes "surdas" passaram a "brandas" ou "sonoras" entre duas vogais, no interior de uma palavra: cáthedram > cathédra > cadeira).

7 Representação do português numa árvore genealógica.

8 Charles Darwin (1809-1882).
} 


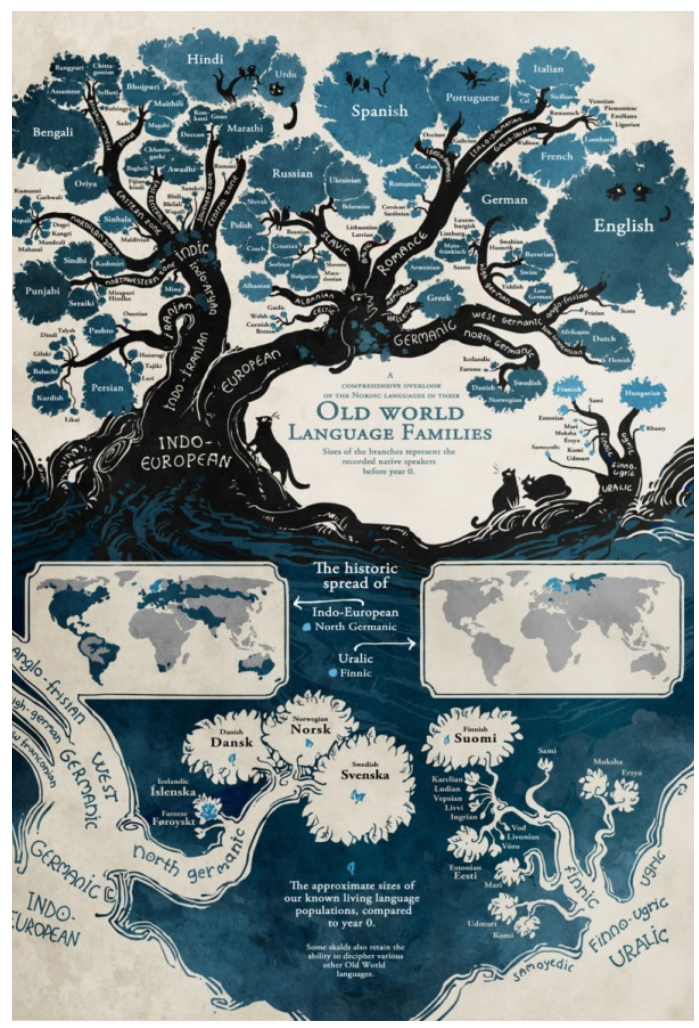

Outros interesses iam aparecendo na investigação sobre diferentes áreas das ciências sociais. Lembre-se, por exemplo, de Wilhelm Wundt, ${ }^{9}$ que propunha que os conhecimentos emergentes da investigação em psicologia com base experimental fossem aplicados na investigação em linguística.

A investigação das línguas deu, a pouco e pouco, lugar à investigação sobre o que é uma língua e como se pode entender a sua natureza. Foi este o ensinamento que nos transmitiu Ferdinand de Saussure.

\subsection{FERDINAND DE SAUSSURE: A LÍNGUA COMO ESTRUTURA}

Estava-se na segunda metade do século XIX e início do século XX. Em 1916 Ferdinand de Saussure deu em Genève um Curso de Linguística Geral que veio depois a ser publicado por dois dos seus alunos. ${ }^{10}$ O curso expandiu-se na Europa e teve uma espantosa importância seminal entre os estudiosos das línguas, já que o seu objetivo era a explicação da natureza da língua e da linguagem. Neste curso, pela primeira vez, Saussure apresentou a 
língua como sistema. O funcionamento dos sistemas e as relações entre os seus elementos constituíram, à época, uma explicação inédita da análise da língua que não se baseava no significado das unidades linguísticas, mas na sua presença na construção da forma. Por oposição, também o estudo tradicional dos linguistas que se voltava para as alterações das unidades (quase sempre fonéticas ou morfológicas) estava agora ocupado com a construção do que era sincrónico por oposição ao diacrónico. Na sequência do aprofundamento destes conceitos foram introduzidos o valor funcional dos elementos do sistema e o caráter sistemático e abstrato da língua como um conjunto de relações entre sistemas. Os elementos do sistema eram definidos por equivalência ou oposição, constituindo cada par do elemento com o seu oposto, uma dicotomia. O signo linguístico com as suas duas faces (o significado e o significante) era o âmago dos novos estudos. A língua e a fala diferiam numa oposição distintiva em que a língua passa a considerar-se com funcionamento autónomo, autossuficiente, em que um dos termos só tem valor quando se opõe a outro. Os elementos que constituem a língua formam a sua estrutura. $\mathrm{O}$ termo estruturalismo, cunhado com base em 'estrutura', expandiu-se na Europa trazendo consigo o novo entendimento do estudo das línguas, e impulsionando o desenvolvimento da mais relevante corrente de investigação em ciências sociais na Europa do século XX.

\subsection{LEONARD BLOOMFIELD: O ESTRUTURALISMO NORTE-AMERICANO}

Cerca de vinte anos depois da publicação do Curso de Saussure, Leonard Bloomfield apresentou nos Estados Unidos, em 1933, o seu conceito de língua de acordo com a perspetiva behaviorista do comportamento humano. A conceção do uso da língua e a sua concretização foram representadas por Bloomfield num esquema do ato de comunicação"11 em que um estímulo exterior (S) levava alguém a falar ( $r$ ) e que essa resposta constituía um estímulo linguístico (s) que, por sua vez, provocava uma resposta linguística (R). $S$ e $R$ pertenciam ao mundo extralinguístico; $s$ e $r$ constituíam o ato linguístico, o que permitia entender o funcionamento da língua como uma resposta a estímulos não linguísticos. Esta perspetiva era também de índole estrutural ao considerar o caráter geral e sistemático da língua. A natureza objetiva e comportamentista da linguística norte-americana permitia o estudo da frequência dos vocábulos e da sua distribuição no discurso, levando ao aparecimento da linguística quantitativa que punha em evidência características das estatísticas linguísticas e de outras relações numéricas.

11 O ato de comunicação foi definido em 1933 na obra fundamental do estruturalismo norte-americano e é ainda hoje o cerne da perspetiva behaviorista de teoria de Bloomfield. 
A recusa do estruturalismo norte-americano em se referir a algo que não fosse diretamente observável e, ao mesmo tempo, a sua preocupação primeira com a descrição das línguas na sua diversidade mostra o caráter empírico desta corrente linguística. Em última análise, a aplicação dos novos métodos permitia um melhor conhecimento da estrutura das línguas e do seu funcionamento. O conceito de estrutura era então uma presença constante nos trabalhos dos linguistas da época, motivando a criação de métodos e técnicas próprios para o estabelecimento dos sistemas das línguas em bases empíricas, o que implicava a recolha de dados organizados em corpora.

\subsection{LÓGICA E LINGUÍSTICA}

O recurso a representações formais ${ }^{12}$ por parte de linguistas norte-americanos trouxe à linguística um maior rigor, a par da integração de métodos recém-criados de análise dos dados recolhidos, e permitiu ainda o tratamento de estruturas frásicas, com a análise, por exemplo, em constituintes imediatos. O momento era chegado para o desenvolvimento de novas teorias em linguística, à semelhança do que se passava com outras ciências sociais como a sociologia, a antropologia ou a arqueologia.

Foi também na primeira metade do século XX que a lógica conheceu um notável impulso ao passar de uma noção filosófica abstrata de "forma" por oposição à “matéria” para a noção de 'forma' no sentido geométrico ou topológico, desenvolvendo assim um raciocínio formalizado. A interação entre lógica e matemática estimulou o progresso em ambas as ciências, e levou à criação de instrumentos teóricos que influenciaram profundamente os estudos linguísticos a partir dos anos 50 . A teoria dos conjuntos, os sistemas formais, a lógica proposicional e de predicados constituíram, nas primeiras décadas a seguir ao meio do século XX, e para várias áreas das línguas, importantes instrumentos formais para o estabelecimento de relações entre estruturas linguísticas. Pela mesma via foram recusadas as explicações que a lógica aristotélica fornecia sobre as relações entre a linguagem e o pensamento. A utilização dos instrumentos formais veio, progressivamente, possibilitar a construção de novos modelos sobre o material empírico e a formulação de hipóteses relativas ao funcionamento linguístico. A sintaxe passou a constituir o cerne da análise e para a sua explicação foram 
criados sistemas de regras que atribuíam uma descrição estrutural às frases de modo explícito e bem definido. ${ }^{13}$

\subsection{NOAM CHOMSKY E JEAN PIAGET: O DEBATE DE ROYAUMONT}

Procuremos agora uma rápida informação sobre as linhas de progresso científico dos estudos linguísticos nos meados do século XX. Nessa ocasião ainda predominava nos Estados Unidos a explicação behaviorista da aquisição da linguagem e do desenvolvimento do ser humano, acreditando-se que o cérebro seria uma "tábua rasa", e as capacidades e propriedades manifestadas no comportamento da criança proviriam dos hábitos e dos dados empíricos a que ela estaria sempre exposta. Aquando da publicação de Verbal Behavior pelo psicólogo behaviorista Skinner, ${ }^{14}$ Noam Chomsky fez uma dura crítica à exposição da teoria e à capacidade para explicar o desenvolvimento humano, e iniciou a construção de uma teoria geral baseada na existência de uma faculdade universal e inata que permitia a cada ser humana adquirir a linguagem naturalmente. Ao aceitar a faculdade da linguagem, Chomsky estava de acordo com a hipótese da existência da "faculdade da linguagem" proposta por René Descartes no século XVII. A rapidez da aquisição da linguagem pela criança e a regularização com que o consegue fazer perante dados lacunares eram, para Chomsky, evidências do funcionamento da faculdade da linguagem na aquisição da língua materna. Esta hipótese e os seus pressupostos, bem como os desenvolvimentos posteriores da teoria chomskiana, permitem atribuir à teoria generativa o caráter de mentalista.

Na Europa, desde os anos 40, o psicólogo e biólogo Jean Piaget também procurava a explicação do funcionamento cognitivo na aquisição da língua materna. Segundo Piaget, numa hipótese que ele mesmo apresentou nas obras sobre epistemologia genética, "o conhecimento não procede nem da experiência única dos objetos nem de uma programação inata pré-formada no sujeito, mas de construções sucessivas com elaborações constantes de estruturas novas". Sem defender uma perspetiva bvehaviorista, Piaget afastou, por assim dizer, a hipótese da existência de uma faculdade da linguagem universal e inata.

Dado o posicionamento diferente de Chomsky e Piaget sobre uma questão fundamental para as ciências humanas, e tendo em conta a importância destes dois investi-

$13 \mathrm{Na}$ esteira do interesse que o modelo estrutural despertou na Europa, o dinamarquês Louis Hjelmslev criou, em 1931, o Círculo Linguístico de Copenhague (CLC). Foi no seio da linguística de Hjelmslev que surgiu a Glossemática cujo objetivo se centrava na procura dos modos de constituição de todo e qualquer fenómeno de produção de significação e de sentido. Posteriormente, a semiótica passou a aplicar-se quase exclusivamente ao estudo dos signos como unidades da semiose.

14 Esta referência serve para localizar no tempo a obra de Skinner que foi publicada em artigos e na Internet. 
gadores, foi organizado um debate que teve lugar em 1975, na Abadia de Royaumont, em que ambos argumentaram em favor da respetiva teoria. Na sequência desse debate, os defensores das duas perspetivas foram depois apelidados de inatistas e construtivistas: os inatistas defendiam que uma faculdade de linguagem pode preexistir na mente, ao passo que os construtivistas consideravam que o comportamento e o desenvolvimento da linguagem resultavam de uma construção do conhecimento e da personalidade do indivíduo.

A utilização destes termos e conceitos tem provocado uma abusiva simplificação por ignorância dos seus fundamentos filosóficos, psicológicos e sociológicos. Quando se tem acesso ao debate de Royaumont percebe-se que as posições de Chomsky e Piaget não são tão distantes quanto se poderia $c r e r .{ }^{15}$ As pretensas coincidências entre uma perspetiva linguística teórica e uma convicção religiosa devem, portanto, ser consideradas como inadmissíveis utilizações de investigações científicas.

\subsection{CHOMSKY E A GRAMÁTICA GENERATIVA}

Na perspetiva de Chomsky o conceito de gramática generativa começou a ser entendido desde as primeiras obras como um mecanismo finito que permite gerar (engendrar) o conjunto infinito das frases gramaticais de uma língua, e somente elas. A partir dos anos 70 a teoria generativa foi integrando novas propostas de Chomsky orientadas na procura de características universais da gramática das línguas. Para o avanço da teoria contribuiu, por um lado, o progresso das ciências da cognição e, por outro, a superação de uma formalização demasiado abstrata e demasiado dependente das idiossincrasias das línguas. O programa minimalista proposto por Chomsky (um programa e não "uma teoria") é uma linha de investigação em que trabalham muitos linguistas desde o início dos anos $90^{16}$. O progresso das ciências da cognição tem igualmente contribuído para a investigação sobre aquisição da linguagem, através, por exemplo, de estudos similares ao da variação dos genes da linguagem e da possível influência sobre problemas de aprendizagem da fala. A utilização de instrumentos formais e de novos modelos vem dar corpo às propostas que têm surgido nos últimos anos.

\footnotetext{
15 Além disso, não se pode inferir, a partir da obra de Chomsky, que a existência desta faculdade universal e inata sirva de prova da existência de um ser criador que decorre de uma fé religiosa. Também não se pode inferir da obra de Piaget que o cérebro seja uma "tábua rasa" no sentido em que geralmente é usada esta expressão.

$16 \mathrm{O}$ conceito de Merge, operação computacional simples recentemente proposta, parece resolver alguns problemas, mas precisa de ser experimentada e testada.
} 


\subsection{A IMPORTÂNCIA DE JAKOBSON NA CRIAÇÃO DO FUNCIONALISMO}

Olhando para o conteúdo desta conferência sobre tantos e tão notórios linguistas, não podia deixar sem referência Roman Jakobson, ${ }^{17}$ um do mais importantes e fecundos linguistas do século XX. Das suas muitas incursões em várias áreas destaco a contribuição para uma 'teoria da comunicação' no âmbito do Círculo Linguístico de Praga, fundado em 1926, o conceito e a aplicação de traços distintivos em fonologia (com Fant e Halle ${ }^{18}$, em 1952) e, evidentemente, sublinho o seu contributo para os estudos funcionalistas com a publicação das Funções da Linguagem nos anos 50.

\subsection{O FUNCIONALISMO LINGUÍSTICO}

Foi com Jakobson que o funcionalismo atraiu primeiro a atenção dos linguistas e ganhou um incremento assinalável. No decurso da segunda metade do século XX e durante o século XXI os estudos funcionalistas proliferaram. Partindo da conceção da língua como um instrumento de interação social, o funcionalismo linguístico passou a considerar a língua sob uma perspetiva interacional que incorpora, assim, as intenções comunicativas dos interlocutores. Seguindo uma linha de investigação de tradição britânica ${ }^{19}$, estipulou que a língua se organiza em torno de duas possibilidades alternativas: a cadeia (o sintagma), e a escolha (o paradigma). Uma gramática funcional seria não um conjunto de regras, mas uma série de recursos para descrever, interpretar e fazer significados.

A partir da análise da língua em uso, a linguística funcionalista espraia-se em diversas linhas de investigação teórica e aplicada, analisando a conversação, o discurso e a interação. É também a fala que permite a função da consciência e do comportamento como objeto de estudo, as regularidades e as regras que estão para além das estritamente gramaticais e que têm como escopo a análise do discurso ou da conversação. Na área do funcionalismo inclui-se também a pragmática linguística. A mudança que a língua exibe (no tempo e no espaço) e a sua própria análise está também sujeita a mudança.

\footnotetext{
17 Jakobson (1896-1982) abriu as portas a milhares de linguistas, levando-os a compreenderem as Funções da Linguagem, a sua importância e o seu uso no comportamento humano. Lembre-se, por exemplo, do papel das ou da, contribuição do tratamento dos traços linguísticos para o desenvolvimento da fonologia generativa.

18 Ver bibliografia.

19 Com influências de John Rupert Firth (1890-1960).
} 


\section{FALEI NO INÍCIO DESTA CONFERÊNCIA DA NATUREZA CIENTÍFICA DA LINGUIISTICA. E AGORA, ONDE ESTÁ A CIÊNCIA? ALGUMAS REFLEXÕES SOBRE CIÊNCIA}

Assinalei até agora diferentes momentos da linguística em que a investigação se serviu de instrumentos desenvolvidos por outras ciências, ou resultantes da sua própria reflexão, na tentativa de conseguir uma explicação cada vez mais satisfatória do funcionamento das línguas e da linguagem. Mas a menção a tantos passos iniciais, e sempre seminais, significará que estamos diante de uma ciência? Também poderemos levantar a seguinte questão: "Para a atribuição do carácter de ciência a um conhecimento, será suficiente que se utilizem instrumentos de natureza científica na investigação do seu objeto específico, ou serão necessárias outras condições?". Uma questão sob a forma de pergunta cuja resposta exige um breve excurso pela epistemologia das ciências.

Se pretendemos aproximar-nos da ciência, temos que ir um pouco mais longe na interpretação da sua natureza. Segundo Ruse, a ciência é "o mistério de todos os mistérios" e a questão principal para o desvendar parece consistir no facto de "considerarmos a ciência como algo diferente, de certo modo especial - algo com padrões independentes que, de alguma forma, garantam a sua verdade e importância e que mereçam o apoio da sociedade" ${ }^{20}$ Convicta eu de que a ciência é importante e procura garantir a verdade, e certa de 'beneficiar do apoio da sociedade' avanço para uma definição sucinta: "Ciência é uma forma de conhecimento com que se pretende explicar o que vulgarmente denominamos 'o real', elaborada essa explicação de tal modo que seja possível a sua validação, ou a sua aptidão para abrir novos domínios do pensamento".

Para alcançar uma definição mais completa e desenhar a sua aplicação, é necessário escolher os instrumentos com que se vai trabalhar, e supor, ou recusar, as características da teoria em que se vai integrar o objeto de análise (neste caso, a linguagem e lou as línguas). Na primeira parte desta conferência apresentei princípios e modelos para explicar a escolha que foi sendo feita perante as novas teorias que ocorreram com o passar do tempo, na convicção de que essa substituição se aproximava mais do que se pretendia. Cheguei a evidenciar a preferência pela gramática generativa, ou pela teoria generativa, com esse desiderato. Tal não significa, porém, que a considere a melhor em todas as circunstâncias. De resto, se escolhermos a teoria generativa, ou qualquer outra teoria formal, teremos de sopesar o que essa escolha implica em termos dua sua capa-

20 Estas considerações sobre ciência são largamente desenvolvidas na obra de Ruse (1999, p. 35). 
cidade de representar formalmente as dimensões do objeto de análise; da capacidade de formular hipóteses explicativas; e da capacidade de proceder à verificação dos resultados das hipóteses formuladas. É evidente, na realidade, que as teorias chamadas formais respondem mais satisfatoriamente à definição da natureza da ciência do que os modelos não formalizáveis, dadas as suas capacidades de generalização e de verificação dos resultados das hipóteses formuladas.

Para além desta questão teórica que reforça a escolha de uma teoria como instrumento de trabalho, é indispensável definir o objeto do conhecimento em todas as dimensões que forem pertinentes para a sua explicação, o que significa explicitar o material do objeto de análise com que vamos trabalhar: os sons, as categorias e as estruturas das línguas, e também as estruturas, as relações e as funções dos elementos do objeto a analisar.

Um segundo aspeto que pertence à natureza da Ciência tem que ver com a forma como intervém a localização no tempo e no espaço, ou seja, o que é atualmente a Ciência para os que a ela pretendem dedicar-se.

\section{RELAÇÃO ENTRE LINGUAGEM E COGNIÇÃO}

O objeto de análise da Linguística comporta, sem dúvida, o estudo das línguas na sua aparente diversidade. Mas as línguas são formas do comportamento humano, ligadas, como todas as formas do comportamento, aos processos cognitivos. Assim, o estabelecimento da relação entre línguas e cognição é indispensável, sob pena de estarmos a dissociar, na investigação, duas dimensões do mesmo objeto e de não podermos atingir, e muito menos explicar, nenhum aspeto relevante do seu funcionamento.

Ora os progressos realizados no conhecimento dos processos cognitivos - em que se destacam a neurobiologia e a genética - permitem afirmar que esses processos decorrem de uma mesma base genética que é universal. Essa capacidade no que respeita à atividade da fala, é a faculdade da linguagem, tão perfeita que permite construir, com poucas dezenas de sons, organizados em categorias e estruturas, uma infinidade de expressões que revelam aos outros o que pensamos, o que imaginamos e o que sentimos.

Mas a sua existência universal não é apenas uma hipótese assente nas duas premissas atrás enunciadas, ou seja, a universalidade dos processos cognitivos e a forma como todos os homens adquirem a fala. Um outro facto vem evidenciar a existência da faculdade universal da linguagem. Refiro-me à aquisição da linguagem feita por todas as crianças em tempo incrivelmente breve e perante dados lacunares em relação à competência rapidamente adquirida. Essa aprendizagem não pode provir senão de um mecanismo cognitivo preparado especialmente para esse fim, mecanismo universal e 
genético. Se tal mecanismo é universal, então a relação entre a gramática das línguas e a faculdade da linguagem também é universal.

Como se entende assim a diversidade das línguas? Bem, o conhecimento que temos da deriva das línguas pode levar-nos a concluir que, se cada uma delas foi evoluindo no tempo, a separação entre elas aprofundou as diferenças. O que disse atrás sobre a relação entre capacidades universais do cérebro e aquisição da linguagem aponta para outro objetivo que inter-relaciona o estudo das línguas com o da aquisição da linguagem. E esse objetivo é procurar, na diversidade linguística de superfície, os traços que pertencem a todas as línguas, ou seja, os traços de um estado inicial interior que poderemos chamar, como Chomsky, o "mecanismo de aquisição da linguagem". Este mecanismo que, ainda segundo Chomsky, "toma a experiência como 'input' e fornece a língua como um 'output" , existe no conhecimento que cada falante tem da gramática da língua que usa, e que mantém presente a interação da produção da língua e dos processos cognitivos que concorrem para essa produção. Chamemos-lhe competência universal, chamemos-Ihe gramática universal.

Ao proceder assim, a linguística conforma-se com a primeira característica do conhecimento científico atrás postulada, procurando uma explicação do "real" (neste caso, a linguagem e as línguas) e não apenas uma descrição. Tendo definido o objeto da ciência da linguagem nas suas dimensões pertinentes, podemos perguntar então que modelo teórico (ou que teoria) se adequa à sua explicação.

Revendo os vários passos do raciocínio que desenvolvi até aqui, eles apontam para uma teoria linguística cujo objetivo seja o estudo das línguas entendidas como constituídas por expressões que são geradas pela gramática interior dos falantes e são continuamente adaptadas a cada situação para produzir, tomando as palavras de Humboldt, "um uso infinito com meios finitos". Essa é a finalidade da descrição das línguas, e os instrumentos utilizados nessa descrição terão de ser os mais adequados, também, à sua explicação. Citando ainda Chomsky: "para satisfazer a condição de adequação explicativa, uma teoria da linguagem necessita de mostrar como cada língua particular pode ser derivada de um estado inicial pela experiência (de cada falante), sob um conjunto de condições limitadas (boundary conditions)".

\section{O PARADIGMA E A MUDANÇA DE PARADIGMA}

Está portanto respondida a pergunta atrás formulada: a ciência impõe a criação de uma teoria formalizável que permita englobar todas as dimensões pertinentes do objeto em análise e explicar, adequadamente, a convergência dessas dimensões. Sobre a condição da pertença de uma teoria a um certo paradigma, e sobre a afirmação de que existe tal 
paradigma e de que pode ser validado, acompanho as seguintes observações: "A ciência é como uma rede que tenta capturar a realidade nas suas malhas". Segundo Gödel, o potencial de refutação é a marca da ciência genuína.

A partir do momento da sua criação e aceitação pela comunidade científica, a teoria enquadrante provoca uma rutura epistemológica no conhecimento científico e, para seguir Kuhn, a ciência entra num novo paradigma. Para que o modelo em que se integra um novo estudo das línguas possa ser considerado como um novo paradigma, é necessário que ele evidencie três características essenciais do conhecimento científico: maior poder explicativo do objeto analisado, estipulação de generalizações e uma abertura para a integração de toda a espécie de problemas a serem resolvidos pelos cientistas. Do cruzamento entre as teorias nascentes em psicologia com a atenção dada às línguas faladas proveio o que se pode denominar uma mudança de paradigma da ciência da linguagem no sentido dado por Thomas Kuhn. ${ }^{21}$

Podemos agora perguntar-nos se esta teoria, que verdadeiramente imprime carácter científico à linguística e é construída de acordo com as dimensões do objeto de análise, é a melhor para atingir os objetivos que se propõe. E voltando ao início desta reflexão, podemos também perguntar-nos se esses objetivos são os que permitem ao estudo da linguagem sair de uma circular auto-referência e compatibilizar a universal faculdade da linguagem com a diversidade superficial das línguas, de modo harmonioso e satisfatório. Mas para a ciência não existe o 'inteiramente satisfatório', como não existe a demonstração 'verdadeira', visto que, como dizia Gödel (apud HOFSTADTER, 1999) a propósito da teoria dos números, "qualquer teoria que seja suficientemente forte para demonstrar a consistência da teoria dos números é pelo menos tão forte quanto a própria teoria dos números". Mas se é tão forte quanto a teoria cuja consistência está a demonstrar, como pode ela demonstrar essa consistência? Teria portanto que ser uma teoria mais forte. Mas a consistência dessa teoria mais forte também terá de ser demonstrada, para que ela sirva de padrão. E como se demonstrará a consistência deste padrão? A partir de uma teoria ainda mais forte, evidentemente. Só que este raciocínio, que é o núcleo do teorema de Gödel, leva-nos ao infinito, ao indecidível.

Devemos portanto adotar a atitude cética de que nenhuma teoria pode ser mais adequada do que outra para a explicação do 'real' e, no caso que nos ocupa, da linguagem e das línguas? Não, porque se não podemos atingir a 'verdade' podemos, pelo menos, iluminar alguns passos do caminho. E a teoria linguística a que me referi aí está para o provar: 
- criação de uma rede de novas inter-relações;

- aspetos desconhecidos que tomam forma e revelam importância;

- um programa de trabalho que parece promissor;

- descobertas, novas hipóteses.

Enfim, a estrada infinita da ciência que, iniludivelmente, nos projeta no futuro.

\section{REFERÊNCIAS}

BACHELARD, Gaston. Le matérialisme rationnel. Paris: PUF, 1953.

BADIOU, Alain. Le concept de modèle. Introduction à une épistémologie matérialiste des mathématiques. Paris: Maspero, 1970.

BLOOMFIELD, Leonard. Language. New York: Holt, Reinhart and Winston, 1933.

CHOMSKY, Noam. Cartesian Linguistics: a Chapter in the History of Rationalist Thought. New York: Harper and Row, 1966.

CHOMSKY, Noam. New Horizons in the Study of Language and Mind. Cambridge: Cambridge University Press, 2000.

DUARTE, Inês. "Chomsky e Descartes: o Uso Estratégico de um Argumento Cartesiano". In: SANTOS, Leonel R. dos; ALVES, Pedro M. S.; CARDOSO, Adelino (Orgs.). Descartes, Leibniz e a Modernidade. Lisboa: Edições Colibri, 1998: 547-561.

HOFSTADTER, Douglas R. Gödel, Escher, Bach: An Eternal Golden Braid. New York: Basic Books, 1999.

KUHN, Thomas S. The Structure of Scientific Revolutions. Chicago: The University of Chicago Press, 1962.

MALMBERG, Bertil. Les nouvelles tendances de la linguistique. Paris: PUF, 1966.

MOUNIN, George. Histoire de la Linguistique des origines au xxe siècle. Paris: PUF, 1967.

POPPER, Karl. Conjectures and Refutations. The grouwth of scientific knowledge. London: Routledge \& Kegan Paul Limited, 1963.

RUSE, Michael. Mystery of Mysteries: Is Evolution a Social Construction?. Cambridge: Harvard University Press, 1999.

SAUSSURE, Ferdinand de. Cours de Linguistique Générale. Paris: Payot, 1964.

SKINNER, B. F. Verbal Behavior. Cambridge: B. F. Snikker Foundation, 2014 [1957]. 